$\begin{array}{ll}\text { Research Square } & \begin{array}{l}\text { Preprints are preliminary reports that have not undergone peer review. } \\ \text { They should not be considered conclusive, used to inform clinical practice, } \\ \text { or referenced by the media as validated information. }\end{array}\end{array}$

\title{
The role of partners in promoting self-care for misoprostol and sub- cutaneous DMPA in Pakistan
}

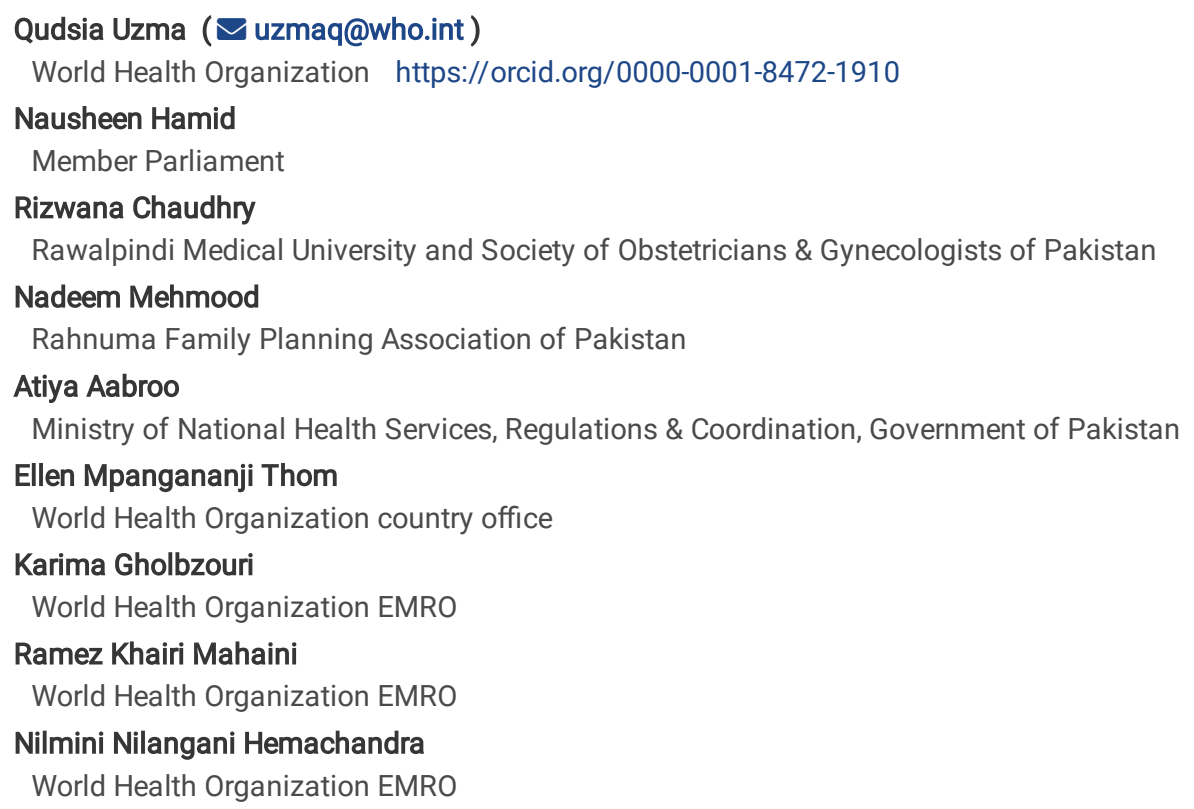

\section{Research Article}

Keywords: Sexual and reproductive health, misoprostol. postpartum hemorrhage, DMPA

Posted Date: March 26th, 2021

DOI: https://doi.org/10.21203/rs.3.rs-339888/v1

License: (c) (1) This work is licensed under a Creative Commons Attribution 4.0 International License. Read Full License

Version of Record: A version of this preprint was published at Health Research Policy and Systems on April 21st, 2021. See the published version at https://doi.org/10.1186/s12961-021-00714-0. 


\section{Abstract \\ Background}

Pakistan is among countries facing protracted challenges in addressing maternal mortality with concomitant weak healthcare system complexed with inequities. Sexual and reproductive health \& rights (SRHR) self-care interventions offer the best solution for improving access to quality healthcare services with efficiency and economy. This manuscript documents country experience in introducing and scaling up two selected SRHR self-care interventions. Prospective qualitative study was used and a semi structured questionnaire was shared with identified SRHR private sector partners selected through convenience and purposive sampling. The two interventions include use of misoprostol for postpartum hemorrhage and use of subcutaneous depomedroxyprogesterone acetate (DMPA) as injectable contraceptive method. Data collection was done through emails and telephonic follow-ups.

\section{Results}

Response was received from 9 out of total 13 partners consulted for the study. The two selected self-care interventions are mainly supported by private sector partners (national and international non-governmental organizations) having national or sub-national existence. Their mandates include all relevant areas like policy advocacy, field implementation, trainings, supervision and monitoring. More partners reported experience related to use of misoprostol; it was introduced more than a decade ago, is registered and being procured by both public and private sectors. Sub-cutaneous DMPA being a new intervention, is recently introduced while commodity availability remains a challenge. It is being delivered through health workers/providers and not promoted as self-administered contraceptive. Community engagement and awareness raising is reported as an essential element of successful field implementation, however, no beneficiary data was collected for the study. Training approaches differ a lot, standalone or integrated with SRHR topics and duration varying between 1 day to 5 days, covering a range of cadres.

\section{Conclusion}

Pubic sector ownership and patronage is essential for introducing and scaling up self-care interventions as a measure to support the healthcare system in delivering quality sexual and reproductive health services. Supervision, monitoring and reporting are areas requiring further support and having leadership and governance role of the public sector. Standardization of trainings, community awareness, supervision, monitoring and reporting is required alongwith integration of self-care in routine capacity building activities (pre and in-service) on sexual and reproductive health in the country.

\section{Background}

The recently conducted demographic and health survey in Pakistan reflected some progress on key maternal and child health indicators in Pakistan.[[i]] Antenatal care -at least one visit (86\%), facility-based deliveries (66\%) and neonatal mortality (42/1000 LB) are among the ones showing reasonable progress. However, the reproductive health/family planning indicators are very slow in progress with a stagnant-in fact, declining-modern contraceptive prevalence rate (CPR 26\%) reflected in the trend of total fertility rate (3.6; 2.9 in urban and 3.9 in rural areas).[1] Since the last census in 1998, the population has grown by $57 \%$ in 20 years and the crude birth rate, though gradually declining, is still alarmingly high at 22 births per 1000 people.[1]

Pakistan is facing a serious challenge of reducing its high maternal mortality ratio (140/100000 LB) [[ii]] with much faster annual rate of reduction in order to achieve the targets (70/100000 LB) set in Sustainable Development Goals 2030 [2]. Pregnant women's chance of survival drops considerably due to the limited Antenatal Care (ANC) $\geq 4$ visits of 36.6 percent in 2012-13 and 51.4 percent in 2017-18, [[iii]] restricted medical supplies, poor healthcare availability and lack of health infrastructure. Preventable maternal morbidity and mortality remains an intimidating and failed public health challenge. Haemorrhage, obstinately contributing as the leading cause of maternal deaths,[[iv]] yet a preventable event in majority of the cases especially through interventions like use of oxytocic such as misoprostol.

Evidence shows that the proportion of pregnancies that are unintended is reportedly on an increasing trend, with high adolescent birth rate (38/1000 girls aged 15-19 years) and an even higher unmet need for family planning (17\%). More than half of these unintended pregnancies resulting in induced abortions and complications related to unsafe abortion is one of the five leading causes of maternal deaths in the country.

The country's baseline for UHC Index unfortunately is reported very low at $40,[[\mathrm{v}]]$ indicative of poor access and use of essential health services and is even worse than Sub-Saharan Africa [5]. The UHC index is reported on a unitless scale of 0 to 100 , which is computed as the geometric mean of 14 tracer indicators of health service coverage. The tracer indicators are organized by four components of service coverage: 1 . Reproductive, maternal, newborn and child health 2 . Infectious diseases 3 . Non-communicable diseases 4 . Service capacity and access. [[vi]] Within the reproductive, maternal, newborn and child health component, the main indicators include modern methods contraceptive prevalence rate and antenatal care $\geq 4$ visits besides two child health indicators. Therefore, country performance on sexual and reproductive health issues has a direct effect on its UHC index.

Main reason for such a poor performance is low coverage of sexual and reproductive health \& rights (SRHR) essential services with serious equity issues and low health care expenditure. In such a situation, where health system is facing chronic challenges in meeting the women's and couples' healthcare needs and ensuring equitable coverage and good quality of SRHR services, it is critically important to promote use of evidence-based self- 
care for SRHR interventions benefitting the masses at large. WHO's definition of self-care is the ability of individuals, families and communities to promote health, prevent disease, maintain health and to cope with illness and disability with or without the support of a health worker.

Self-care interventions recommended by WHO are evidence-based and can include information about a sexual or reproductive health issue as well as ways in which individuals can obtain drugs, devices, diagnostics and /or digital products fully or partially separate from formal health services that can be used with or without the direct supervision of a health worker.

SRHR self-care is being practiced by women for millennia including management of menstruation, contraception, pregnancy and childbirth. With time, self-care has become sophisticated and data-driven. Evidence shows that when people are active participants in their own healthcare, adherence to treatment regimens improves.[[vii]] In the long run, self-care is of economic interest from both a community and a personal perspective, as it effects a relief for the healthcare system and results in changed healthcare seeking behaviors.[[viii]] Self-care can increase the level of engagement and autonomy that people can exercise over their health providing the opportunity of improving equitable access to healthcare, quality of care and financial protection for the users of self-care.[[ix]]

Self-care brings benefits like improving efficiency of healthcare delivery by including users as lay health workers, increasing use of preventive services and adoption of preventive behaviors as well as improving adherence to treatments and reducing need for the formal healthcare services.[[x]]

With current COVID-19 situation, this has become even more relevant and essential. In order to address the sexual and reproductive health status, ensure equitable access to SRHR care services; partners are reporting that they have initiated efforts to ensure communities are sensitized on key SRHR self-care interventions in line with the WHO global recommendations. A rapid exercise of landscaping the current experiences on two selected SRHR interventions: (i) interventions included use of misoprostol for prevention and management of postpartum hemorrhage, and (ii)use of sub-cutaneous DMPA for contraception; was done through online communication with relevant partners in Pakistan. The key objective of this study was to document the implementation of self-care for SRHR interventions experiences in Pakistan context, and identify major challenges for informing future plan and scale-up. This study is the first time to be held in Pakistan and will contribute to the existing literature.

The aim of this study is to document the best practices and lessons learnt from introducing and implementing use of misoprostol and sub-cutaneous DMPA as self-care SRHR interventions. Specific objectives of the study are:

1. To explore the role of partners in planning for implementation of two identified SRHR self-care interventions in Pakistan

2. To determine the implementation processes used by partners for introducing and delivering the two identified SRHR self-care interventions in Pakistan

[i] Pakistan Demographic and Health Survey. Islamabad. National Institute of Population Studies. 2018-19.

[ii]https://www.who.int/gho/maternal_health/countries/pak.pdf?ua=1 Accessed on 15 July 2020

[iii] UN Interagency Group, 2015; Levels and Trends in Child Mortality

[iv] Pakistan Demographic and Health Survey. Islamabad. National Institute of Population Studies. 2006-2007

[v] Khalid F, Brunal MP, Sattar A, Laokri S, Jowett M, Raza W \& Hotchkiss DR. Assessing the Efficiency of Sub-National Units in Making Progress Towards Universal Health Coverage: Evidence from Pakistan. Health Systems \& Reform; 2020. 6:1, D0I: 10.1080/23288604.2019.1617026.

[vi]https://www.who.int/data/gho/indicator-metadata-registry/imr-

details/4834\#: :text=Target\%203.8\%20is\%20defined\%20as,medicines\%20and\%20vaccines\%20for\%20all\%E2\%80\%9D. Accessed on 17 July 2020

[vii] Levinson W, Lesser CS, Epstein RM. Developing physicians communication skills for patient-centered care. Health Affairs. 2010; 29(7):1310-1318.

[viii] Bertil M, Birgitta A, Ann MS, Birgitta G, Barbro H, Bengt F, Promoting medical self-care: evaluation of a family intervention implemented in the primary health care by pharmacies, Family Practice, Volume 16, Issue 5, October 1999, Pages 522-527, https://doi.org/10.1093/fampra/16.5.522

[ix] BMJ 2019;365:I1228. http://dx.doi.org/10.1136/bmj.I1228 Accessed on 17 July 2020

[x] Panagioti M, Richardson G, Small N, et al. Self-management support interventions to reduce health care utilisation without compromising outcomes: a systematic review and meta-analysis. BMC Health Serv Res 2014; 14:356. doi:10.1186/1472-696314-356

\section{Methodology}

It is a prospective qualitative study involving non-governmental organizations (NGOs) in the country as partners who have had any experience of implementing the selected SRHR self-care interventions. The study team including representatives from Ministry of National Health Services, Regulations and Coordination (NHSR\&C), Government of Pakistan, WHO Eastern Mediterranean Regional Office (EMRO) and country office and a partner organization reviewed a detailed list of partner organizations involved in sexual and reproductive health programming in the country to identify 
potential partners having experience in self-care SRHR interventions. Therefore, a convenience sample of partner was derived for seeking inputs on a structured questionnaire.

A simple structured questionnaire (annexed) was developed to capture key highlights of the partner's experiences in introducing/implementing the two SRHR self-care interventions in the country. The questionnaire included sections on basic information of the organization like type of organization, its geographic coverage in the country, technical areas of focus related to SRHR programming. There are specific questions around the partner's involvement in capacity building activities, duration of trainings, approach of training as stand-alone or integrated with other SRHR topics, availability of mater trainers, estimated number and type of providers trained. Other questions related to partner's role in community outreach, monitoring and supervision, data management and reporting as well as specific contributions during COVID-19 response are also included. Their inputs on challenges and lessons learnt is also sought through open ended questions. The questionnaire did not include any data on beneficiaries and no community interaction was included in the methodology.

A list of partners was drafted in consultation with relevant experts in SRHR field and the questionnaire was circulated by the focal point at Ministry of NHSR\&C to all. The questionnaire was shared with a total of 13 partners while two of them informed that they had no relevant experience. Responses were received from $70 \%$ of partners $(n=9)$ and $30 \%$ did not respond despite two reminders on emails. Feedback received was collated and findings were documented accordingly.

A conceptual framework (Figure 1) has been developed to guide the process of documenting country experience in SRHR self-care interventions - use of misoprostol and sub-cutaneous DMPA.

\section{Results}

\section{Organization profile and health coverage through self-care for SRHR interventions}

The findings show that key perpetrators of this important intervention are mainly private sector - civil society organizations working on SRHR in the country. Out of the total 9 respondents, 5 belonged to international non-governmental organizations (NGOs) and 4 were from local NGOs. Key actors involved in SRHR self-care implementation in the country are IPAS, Jhpiego, International Medical Corps, Greenstar Social Marketing, National Committee on Maternal and Newborn Health, AMAAN, Rahnuma-Family Planning Association of Pakistan, Pathfinder International and Riz consulting among others. More than half of the partners involved in introduction/implementation of SRHR self-care interventions have geographic coverage

across all four provinces of Pakistan with 5 out of total 9 respondents having sub-national presence whereas the remaining 4 were working on national scale. Almost all partners have had a role in policy advocacy for SRHR, technical support in guidelines/training modules development, capacity building and follow-up, implementation on the ground as well as supervision and monitoring (Table 1).

\section{Table 1: Organizational profiles related to SRHR programming}




\begin{tabular}{|c|c|c|c|c|c|c|c|c|}
\hline \multirow[b]{2}{*}{ Names } & \multirow{2}{*}{$\begin{array}{l}\text { Experience on } \\
\text { Misoprostol or } \\
\text { SC DMPA? }\end{array}$} & \multicolumn{7}{|c|}{ Organization's profile related to SRHR programming in Pakistan } \\
\hline & & $\begin{array}{l}\text { Policy } \\
\text { advocacy } \\
\text { for SRHR } \\
\text { services }\end{array}$ & $\begin{array}{l}\text { Technical support for } \\
\text { guidelines/ training } \\
\text { modules/ reporting } \\
\text { tools etc }\end{array}$ & $\begin{array}{l}\text { Training } \\
\text { of } \\
\text { trainers }\end{array}$ & $\begin{array}{l}\text { Cascade } \\
\text { training }\end{array}$ & $\begin{array}{l}\text { Training } \\
\text { follow } \\
\text { ups }\end{array}$ & $\begin{array}{l}\text { Implementation } \\
\text { in field }\end{array}$ & $\begin{array}{l}\text { Supervision } \\
\text { and } \\
\text { monitoring }\end{array}$ \\
\hline $\begin{array}{l}\text { IPAS } \\
\text { international }\end{array}$ & Misoprostol & $\sqrt{ }$ & $\sqrt{ }$ & $\sqrt{ }$ & $\sqrt{ }$ & $\sqrt{ }$ & $\sqrt{ }$ & $\sqrt{ }$ \\
\hline Jhpiego & SC DMPA & $\sqrt{ }$ & $\sqrt{ }$ & $\sqrt{ }$ & $\sqrt{ }$ & $\sqrt{ }$ & $\sqrt{ }$ & $\sqrt{ }$ \\
\hline $\begin{array}{l}\text { International } \\
\text { Medical Corps }\end{array}$ & Misoprostol & $\sqrt{ }$ & & & & & $\sqrt{ }$ & $\sqrt{ }$ \\
\hline $\begin{array}{l}\text { Greenstar Social } \\
\text { Marketing }\end{array}$ & Misoprostol & $\sqrt{ }$ & & $\sqrt{ }$ & $\sqrt{ }$ & $\sqrt{ }$ & $\sqrt{ }$ & $\sqrt{ }$ \\
\hline $\begin{array}{l}\text { National } \\
\text { Committee on } \\
\text { Maternal \& } \\
\text { Newborn Health }\end{array}$ & Misoprostol & $\sqrt{ }$ & $\sqrt{ }$ & $\sqrt{ }$ & $\sqrt{ }$ & $\sqrt{ }$ & $\sqrt{ }$ & $\sqrt{ }$ \\
\hline AMAAN & Misoprostol & $\sqrt{ }$ & $\sqrt{ }$ & $\sqrt{ }$ & $\sqrt{ }$ & & $\sqrt{ }$ & $\sqrt{ }$ \\
\hline $\begin{array}{l}\text { Rahnuma- Family } \\
\text { Planning } \\
\text { Association of } \\
\text { Pakistan }\end{array}$ & Both & $\sqrt{ }$ & $\sqrt{ }$ & $\sqrt{ }$ & $\sqrt{ }$ & $\sqrt{ }$ & $\sqrt{ }$ & $\sqrt{ }$ \\
\hline $\begin{array}{l}\text { Pathfinder } \\
\text { International }\end{array}$ & Both & $\sqrt{ }$ & $\sqrt{ }$ & $\sqrt{ }$ & $\sqrt{ }$ & $\sqrt{ }$ & $\sqrt{ }$ & $\sqrt{ }$ \\
\hline Riz Consulting & SC DMPA & $\sqrt{ }$ & & $\sqrt{ }$ & & & & \\
\hline
\end{tabular}

Implementation process:

More than half of the partners were not informed about global WHO guidelines on SRHR self-care interventions while they initiated introduction/implementation of these activities. Majority of partners have experience on misoprostol and few of them have experienced SC DMPA alone or both interventions.

\section{A. Advocacy}

All except one of the partners are involved in policy advocacy on sexual and reproductive health in the country including focus on either or both of the selected self-care interventions. Policy advocacy is found as a mandate adopted by both national and international non-governmental organizations. Misoprostol is an example of the effectiveness of this role as it was first recommended as medicine of choice for postpartum hemorrhage and postabortion care under maternal and newborn healthcare best practices in 2009. Subsequently, it was registered with Drug Regulatory Authority of Pakistan and was included in the essential medicine list. It is being regularly procured by the public and private sector, is also available over the counter at pharmacies at an affordable price and is widely used as a routine care by skilled birth attendants besides being used as self-care intervention.

\section{B. Capacity building activities}

All partners have had capacity building interventions involving various cadres of health providers and communities for use of misoprostol while focusing on medical doctors including midlevel providers for SC DMPA. These trainings were conducted either as separate sessions or integrated with SRHR trainings (figure 2). The duration of trainings has been reported as variable between 0.5 to 5 days depending upon the type of participants (figure 3). For example, pharmacists were oriented in 0.5 day and data collectors were trained in 5 days while pregnant women were sensitized in 0.5 day, managers were trained in 2 days and health providers were trained in 1 day.

Partners have varied experience in imparting trainings; some have conducted as high as 400 training sessions while others have only conducted 1 session (table 2). Trainings sessions on use of misoprostol outnumber that on SC DMPA or both as experienced by some of the partners. The number of providers/managers trained on SRHR self-care interventions range between 30 to more than 2000 by different partners (table 2).

Table 2: Number of trainings and providers trained by partners on self-care SRHR interventions 


\begin{tabular}{|c|c|c|c|c|c|c|c|}
\hline \multirow[t]{2}{*}{ S. } & \multirow[t]{2}{*}{ Name of Organization } & \multirow[t]{2}{*}{$\begin{array}{l}\text { Conducted trainings } \\
\text { on self-care? }(\mathrm{Y} / \mathrm{N})\end{array}$} & \multirow[t]{2}{*}{$\begin{array}{l}\text { Estimated no of } \\
\text { training sessions to } \\
\text { date }\end{array}$} & \multirow[t]{2}{*}{$\begin{array}{l}\text { Estimated no. of } \\
\text { providers trained }\end{array}$} & \multirow[t]{2}{*}{$\begin{array}{l}\text { Duration } \\
\text { of } \\
\text { training }\end{array}$} & \multicolumn{2}{|c|}{$\begin{array}{l}\text { Training } \\
\text { implemented as }\end{array}$} \\
\hline & & & & & & $\begin{array}{l}\text { Separate } \\
\text { session }\end{array}$ & $\begin{array}{l}\text { Integrated } \\
\text { with SRHR }\end{array}$ \\
\hline 1 & IPAS international & Yes & 17 & 1980 & 5 days & $\sqrt{ }$ & $\sqrt{ }$ \\
\hline 2 & Jhpiego & Yes & $>40$ & 666 & 1 day & $\sqrt{ }$ & - \\
\hline 3 & International Medical Corps & No & - & - & - & - & - \\
\hline 4 & Greenstar Social Marketing & Yes & $>60$ & 1900 & $\begin{array}{l}30 \text { min to } \\
0.5 \text { day }\end{array}$ & - & $\sqrt{ }$ \\
\hline 5 & $\begin{array}{l}\text { National Committee on } \\
\text { Maternal \& Newborn Health }\end{array}$ & Yes & 2 & 50 & 0.5 day & - & $\sqrt{ }$ \\
\hline 6 & AMAAN & Yes & $>400$ & $>1000$ & 0.5-1 day & $\sqrt{ }$ & $\sqrt{ }$ \\
\hline 7 & $\begin{array}{l}\text { Rahnuma- Family Planning } \\
\text { Association of Pakistan }\end{array}$ & Yes & 8 & 75 & 1 day & - & $\sqrt{ }$ \\
\hline 8 & Pathfinder International & Yes & 116 & $>100$ & 5-6 days & - & $\sqrt{ }$ \\
\hline 9 & Riz Consulting & No & 1 & 30 & 2 days & $\sqrt{ }$ & - \\
\hline
\end{tabular}

The cadres trained on these self-care interventions include doctors, nurses, midwives, lady health visitors lady health workers and counselors. Project staff, health managers and community volunteers have been trained on use of misoprostol but not on SC DMPA. None of the partners reported training of cadres working under population welfare departments (family welfare workers) to be trained on use of misoprostol although they are included in trainings on SC DMPA (table 3). All partners were in agreement that self-care SRHR interventions present a promising strategy during the current COVID -19 situation for supporting continuation of essential SRHR services.

Table 3: Types of cadres trained by SRHR partners who shared their self-care experience

\begin{tabular}{|c|c|c|c|c|c|c|c|c|c|c|}
\hline \multirow[t]{2}{*}{ S. } & \multirow[t]{2}{*}{ Name of Organization } & \multicolumn{5}{|c|}{$\begin{array}{l}\text { Trained on both self-care interventions (misoprostol and } \\
\text { SC DMPA) }\end{array}$} & \multirow{2}{*}{$\begin{array}{l}\text { Trained } \\
\text { on use of } \\
\text { SC DMPA } \\
\text { Family } \\
\text { Welfare } \\
\text { Workers }\end{array}$} & \multicolumn{3}{|c|}{ Trained on use of Misoprostol } \\
\hline & & $\begin{array}{l}\text { Medical } \\
\text { doctors }\end{array}$ & Nurses & Midwives & $\begin{array}{l}\text { Lady } \\
\text { Health } \\
\text { Visitors }\end{array}$ & Counselors & & $\begin{array}{l}\text { Project } \\
\text { staff }\end{array}$ & $\begin{array}{l}\text { Community } \\
\text { volunteers }\end{array}$ & $\begin{array}{l}\text { Program } \\
\text { Managers }\end{array}$ \\
\hline 1 & IPAS international & $\sqrt{ }$ & $\sqrt{ }$ & $\sqrt{ }$ & $\sqrt{ }$ & - & $\sqrt{ }$ & $\sqrt{ }$ & - & $\sqrt{ }$ \\
\hline 2 & Jhpiego & $\sqrt{ }$ & $\sqrt{ }$ & $\sqrt{ }$ & $\sqrt{ }$ & $\sqrt{ }$ & $\sqrt{ }$ & - & - & $\sqrt{ }$ \\
\hline 3 & $\begin{array}{l}\text { International Medical } \\
\text { Corps }\end{array}$ & - & - & - & - & - & - & - & - & - \\
\hline 4 & $\begin{array}{l}\text { Greenstar Social } \\
\text { Marketing }\end{array}$ & $\sqrt{ }$ & $\sqrt{ }$ & $\sqrt{ }$ & $\sqrt{ }$ & $\sqrt{ }$ & $\sqrt{ }$ & - & - & $\sqrt{ }$ \\
\hline 5 & $\begin{array}{l}\text { National Committee } \\
\text { on Maternal \& } \\
\text { Newborn Health }\end{array}$ & $\sqrt{ }$ & $\sqrt{ }$ & $\sqrt{ }$ & $\sqrt{ }$ & $\sqrt{ }$ & $\sqrt{ }$ & - & - & - \\
\hline 6 & AMAAN & $\sqrt{ }$ & $\sqrt{ }$ & $\sqrt{ }$ & $\sqrt{ }$ & $\sqrt{ }$ & $\sqrt{ }$ & $\sqrt{ }$ & $\sqrt{ }$ & - \\
\hline 7 & $\begin{array}{l}\text { Rahnuma- Family } \\
\text { Planning Association } \\
\text { of Pakistan }\end{array}$ & - & $\sqrt{ }$ & $\sqrt{ }$ & $\sqrt{ }$ & - & - & - & - & $\sqrt{ }$ \\
\hline 8 & $\begin{array}{l}\text { Pathfinder } \\
\text { International }\end{array}$ & $\sqrt{ }$ & - & $\sqrt{ }$ & $\sqrt{ }$ & - & $\sqrt{ }$ & $\sqrt{ }$ & - & $\sqrt{ }$ \\
\hline 9 & Riz Consulting & $\sqrt{ }$ & - & $\sqrt{ }$ & $\sqrt{ }$ & $\sqrt{ }$ & - & - & - & - \\
\hline
\end{tabular}

\section{Field implementation}

Partners involved in SRHR programming in the country supported introduction /implementation of SRHR self-care interventions. With their capacities in policy advocacy, imparting trainings, reporting, supervision and monitoring, they reported to have been able to address implementation challenges. In 
order to promote self-use of misoprostol, partners used different strategies. One approach was to distribute "Safe Delivery Kits" with 3 tablets of Misoprostol (with instructions in local language for normal delivery, newborn care, and PPH prevention with the Misoprostol) in addition to a dignity sheet, apron, soap, cord clamp etc in the kit. These were given to all pregnant women in camps and even hospitals wards, to ensure active management of third stage of labor (AMTSL) took place. The women were instructed that they must take these 3 tabs oral/S/L after baby was born. Other strategies like use of helplines to address frequently asked questions and community follow-ups are also adopted by partners. Field implementation experiences show that even the rural women with low literacy welcome learning on SRHR self-care. They follow instructions and take the responsibility provided they receive clear guidance. Effective counselling with users can support continuity of SRHR self-care and greatly reduced the need for referral of PPH cases to hospitals (in case of misoprostol). Experience from the field implementation indicate that user friendly gadget (like SC-DPMA) can promote uptake of contraception, however, the government's role to ensure enabling environment and commodity security is highly essential.

\section{Supervision \& Monitoring}

For monitoring and supervision, most of the partners have reported using a systematic process including on-the-job mentoring, refreshers, follow-ups, field supervisory visits and regular reporting strategies. Majority of partners are not sharing the relevant data with government counterparts as a routine. Information sharing is done through dissemination events by some partners.

\section{E. Commodity availability}

In terms of the commodity availability, it is important to note that misoprostol is registered in the country and is included in the essential medicine list for management of PPH. This was made possible through sustained advocacy by partners whereby succeeding in its registration by Drug Regulatory Authority of Pakistan following which it is being procured widely by both public and private sectors and is readily available in the market. On the contrary, SC DMPA is a newly introduced contraceptive methods and is being imported by organizations involved in its introduction and implementation. It is yet to be registered and included in the essential list of contraceptive methods. Partners reported procurement of these commodities by their organization or by another organization and supplied to their organization (including donation from a pharmaceutical company). For misoprostol, clients may also need to have out-of-pocket payment in situations where it is not made available free of cost by the provider. In case of SRHR self-care interventions, there is a lot of reliance on over-the-counter availability of commodities and supplies, therefore, it is of utmost importance to ensure capacity building and on-boarding of chemists/pharmacists to facilitate the introduction/implementation of SRHR self-care interventions in the country.

\section{F. Community awareness}

The partners who had reported being informed of the global WHO guidelines on SRHR self-care interventions also indicated that they played a key role in enhancing community awareness on the use of identified self-care SRHR interventions. This included orientation sessions with pregnant women, counselors, lady health workers and community volunteers as well as with informal providers like the pharmacists to be able to contribute to the community awareness.

\section{G. Public sector patronage}

For misoprostol, ownership by the public sector in particular for its procurement and distribution through the public sector healthcare delivery system has been pivotal in its wide scale implementation. Similarly, SC DMPA is also introduced in consultation with the public sector mainly with consent of the Population Welfare Department in Sindh province where it was piloted for the first time in 2018. For both the interventions, all capacity building activities involved mainly the public sector providers and managers besides some project staff, volunteers and community members.

\section{Self-care interventions during COVID-19 response}

All partners were in agreement that COVID-19 response has brought opportunities for expanding use of self-care SRHR interventions. Only 2 out of 9 reported having no active role during COVID-19 response in community outreach wit focus on SRHR self-care interventions. Among the partners who responded positively, various alternative strategies have been reported for reaching out to the communities remotely. These included setting up a SHRH telehealth line (toll free) linking communities with expert clinicians to provide SRHR consultations; use of E-messages and telehealth besides the use of conventional approaches like community educators, $24 / 7$ helpline etc. However, commodity security remains a key concern for all and limits the expansion of such alternate strategies to benefit larger population.

\section{Discussion And Conclusion}

Use of misoprostol as SRHR self-care intervention in Pakistan is being implemented for more than a decade now mainly perpetuated through the private sector. It was introduced much before recommendation by WHO as self-care intervention and most of the partners are not aware even now about the global WHO guidelines on SRHR self-care interventions. SC DMPA, however, is a newer contraceptive method and has been introduced recently with support from private sector partners. Within Pakistan, there has been little integration of self-care interventions into the public sector capacity building or service delivery mechanisms. 
In line with the conceptual framework for the WHO consolidated guideline on self-care for health, [[i]] findings from this study reveal that "people centred" approach remains the core objective of promoting self-care interventions with the objective of empowering communities. Similarly, the enabling environment for such introduction and field implementation required "health systems" components like service delivery, essential medicine, human resources and information systems etc. In the same connection, the places of access and roles of pharmacies or digital platforms as well as the communities themselves are closely linked with the introduction, uptake and scale-up of self-care interventions.

Policy advocacy on sexual and reproductive health is part of the organizational mandate of almost all partners involved in the SRHR self-care interventions providing the opportunity to these partners to contribute to the creation of enabling environment through sustained advocacy on promoting SRHR self-care interventions in the country. A relevant example is that of misoprostol. With sustained advocacy of public health practitioners, misoprostol was included in the list of essential medicines for management of post-partum hemorrhage after the launch of MNCH Best Practices in 2009 [Karachi Declaration 2009). [[ii]]

Field implementation is another mandate shared by many partners who responded to this study. Despite that fact that majority of them were not aware of the WHO recommended SRHR self-care interventions, they played a critical role in introduction and scale-up of these interventions in the country. The key factors for this interest and motivation on part of the partners to promote these interventions were the scientific evidence behind use of the medicine (misoprostol \& SC DMPA). Other reasons include the greater need for engaging women and communities during crisis like the floods in 2010 and the poor situation of family planning indicators as reported in the DHS 2018 emphasizing the dire need to address uptake of contraceptive methods preferably by self-administration. It is pertinent to note that despite the WHO recommendation on self-administration of SC DMPA, in Pakistan, the introduction phase is involving community-based workers (lady health workers) for providing the FP commodity with the plan for scalingup through women's self-administration in future. Research across several countries has demonstrated that most women are able to self-inject SC DMPA provided they have been offered proper training.[[iii]] Therefore, once the self-administration of SC DMPA is officially allowed in the country, the implementation approach can be easily modified to involve women for self-use rather than relying on the health workers.

Capacity building of human resources is an important element of successful implementation. A good practice statement in the WHO guidelines on selfcare highlights the importance of trained human resource - "health-care workers should receive appropriate recurrent training and sensitization to ensure that they have the skills, knowledge and understanding to provide services". [[iv]] Almost all partners (except one) have reported having significant contributions in capacity building of health workforce including various cadres like doctors, nurse, midwives, counselors, community-based workers and volunteers alongwith managers. It is pertinent to note that trainings on misoprostol rarely include cadres from population welfare departments (i.e. family welfare workers) whose prime focus is on family planning services and are not counted as skilled birth attendants. On the contrary, the same cadre is among the others who receive trainings on use of SC DMPA since they are all expected to deliver family planning services. However, the training approaches being used by partners are quite varied. The topics are either used separately or integrated with the SRHR trainings with total duration between half day to 5 days as reported by partners. These varied approaches indicate the need for having a standardized training material for ensuring quality of trainings and also avoiding any conflicting messages being forwarded to the communities and women due to lack of a standardized training content. The Global Values and Preferences Survey (GVPS) found that many health-care providers wanted more training or information about these self-care interventions and were also concerned about incorrect use by patients and not accessing health care if/when needed. WHO guidelines emphasize that for promotion and facilitation of self-care interventions for sexual and reproductive health and rights (SRHR), it is important that training for health workers incorporates: communication to enable informed decision-making; values clarification; interprofessional teamworking; and empathetic and compassionate approaches to care. [13] It is therefore essential for sustained scale-up in Pakistan to have standardized training approaches with focus on the key elements as per the global guidance. An equally important aspect is training of the users on self-administration, self-monitoring and self-awareness. The WHO guidelines recommend that health-care providers in low-resource settings may find the option to task-shift the administration of injectable contraception to clients themselves acceptable, as long as effective training can be provided, and the safety of users can be assured. However, while doing so, it must be ensured that the users/clients are given the option to still seek services from health care providers for such interventions, if they prefer so or are hesitant or concerned about doing so themselves.

In Pakistan experience, training of communities esp. women have been focused by some partners and this needs to be applied across the board as a pre-requisite for introducing and scaling up self-care SRHR interventions.

Although self-care interventions are recommended by WHO for adoption by communities in the larger interest of universal health coverage and being cost-effective for the end-user, but higher initial investment by the health system is required for the provision of training, supervision and monitoring [10]. However, for cervical cancer screening, the recommended self-care intervention is found to be associated with increased uptake (women twice likely to self-use) regardless of supervision. In the experience from Pakistan, use of misoprostol has been widespread without much documented supervision by partners and the public sector healthcare system. On the other hand, SC DMPA is not yet allowed as a self-administered contraceptive and is being delivered through health providers and community-based health workers to ensure appropriate usage and reporting on the same. Likewise, for the health workforce involved in promoting and implementing user-led approaches and autonomy through self-care interventions, pre- and in-service training and on-the-job supervision are equally important. Moreover, a fair number of recommendations by WHO on self-care interventions require an assurance of targeted monitoring and follow-up or referrals to ensure that the users are well supported by healthcare system. Self-monitoring by users brings benefits like reduced frequency of hospital visits and increased uptake of self-care medical devices or commodities. [14] Monitoring and oversight are also important to ensure that standards are implemented and maintained. It is important to provide mechanisms for anonymous reporting to anyone who may experience stigma and/or discrimination when they try to obtain health services. [10] 
Commodity security is another critical element for ensuring scale-up of self-care intervention. Subsequent to its registration and inclusion in essential medicine list in Pakistan, misoprostol is now routinely procured by the government departments of health, became easily available at affordable price and being used widely at healthcare facilities in both public and private sector. This availability has eased out the use of misoprostol for medical abortion as per the global guidelines is also practiced in the country although the medicine was only registered for PPH. Almost all partners have reported issues in availability of SC DMPA as all supplies have been imported for the sake of operational research and early introduction managed by UNFPA in 2018 and 2019. New and improved products and tools may help women exercise autonomy over their sexual and reproductive health using the self-care interventions, however, continuous uninterrupted availability of commodities and tools remain a challenge worldwide. Professional groups like the Oral Contraceptives Over-the-Counter Working Group which maps global availability have been advocating this for long that women need to be given the control by allowing non-prescription access to oral contraceptives.[13] The same would hold true for other commodities and tools as per the recommended self-care interventions including misoprostol and SC DMPA.

Community awareness especially orientation of women about the self-care interventions needs to be further enhanced by all partners as well as the players in public sector. Just as trainings are necessary for the health workforce, women would also require support and orientation on use of self-care

interventions - at times with back-up from the relevant health workforce. Encouraging, preparing and supporting women and girls to take ownership of certain aspects of their SRHR care can lead to multiple benefits for both the health system and the users. These include women learning about their bodies and having increased self-sufficiency and health workers freed up to devote more time for other medical conditions.

\section{Study limitations:}

This paper used a prospective qualitative study design to enquire about the self-care implementation experiences using a feasible sample of selected partners (mainly non-governmental organizations). [14] Emails and telephonic communication were used with a pre-structured questionnaire as a relevant data collection technique.[[v]] The validity and reliability are also considered sufficient as the questions were constructed by a group of public health experts and were adequately responded by the partners. Few partners declined only because they didn't have sufficient implementation experience to report. There were no questions included to capture the details about community engagement and beneficiary data.

[i] WHO consolidated guideline on self-care interventions for health: sexual and reproductive health and rights. Geneva: World Health Organization; 2019. Licence: CC BY-NC-SA 3.0 IGO.

[ii]https://phkh.nhsrc.pk/sites/default/files/feeds/Karachi\%20Declaration\%20MNCH\%20and\%20FP\%20Best\%20Practices\%20Pakistan\%202009.pdf Accessed on 20 July 2020

[iii] Path.azureedge.not/media/documents/RH_Outlook_Nov_2017.pdf Accessed on 20 July 2020

[iv] Burns N, Grove SK. The Practice of Nursing Research; Conduct, Critique and Utilisation. Philadelphia: W.B. Saunders Co, 1993.

[v] Rapley P. Self-care: re-thinking the role of compliance. Aus J Adv Nurs 1997; 15:20-25.

\section{Declarations}

- Ethics approval and consent to participate

\section{Not applicable}

- Consent to publish

\section{Not applicable}

- Availability of data and materials

All data generated or analysed during this study are included in this published article and supplementary information files have also been uploaded.

- Competing interests

The authors declare that they have no competing interests

- Funding

\section{Not applicable}

Publication costs are being covered by WHO HQ as the supplement issue is supported for SRHR self-care experience sharing from EMRO region.
- Authors' contributions

QU collated the information, prepared results, drafted manuscript, incorporated feedback and submission to the journal 
NH reviewed the draft and provided guidance on finalizing it

RC supported in identification of potential partners and drafting the tool

NM supported in identification of potential partners and coordinating with them for data collection

AA supported in identification of potential partners, coordinating with them for data collection and reviewing the draft manuscript

ET reviewed the draft and provided guidance on finalizing it

KG reviewed the draft manuscript, guided on presentation of results and provided feedback for finalizing it

RM reviewed the draft and provided guidance on finalizing it

NH reviewed the draft and provided guidance on finalizing it

\section{All authors read and approved the final manuscript}

\section{- Acknowledgements}

The contributions from partner organizations are duly acknowledged for sharing information to develop this manuscript. The partner organizations include: IPAS, Jhpiego, International Medical Corps, Greenstar Social Marketing, National Committee on Maternal and Newborn Health, Association for Mothers and Newborns, Family Planning Association of Pakistan, Pathfinder International and Riz consulting.

\section{References}

1. Pakistan Demographic and Health Survey. Islamabad. National Institute of Population Studies. 2018-19.

2. https://www.who.int/gho/maternal_health/countries/pak.pdf?ua=1 Accessed on 15 July 2020

3. UN Interagency Group, 2015; Levels and Trends in Child Mortality

4. Pakistan Demographic and Health Survey. Islamabad. National Institute of Population Studies. 2006-2007

5. Khalid F, Brunal MP, Sattar A, Laokri S, Jowett M, Raza W \& Hotchkiss DR. Assessing the Efficiency of Sub-National Units in Making Progress Towards Universal Health Coverage: Evidence from Pakistan. Health Systems \& Reform; 2020. 6:1, D0I: 10.1080/23288604.2019.1617026.

6. https://www.who.int/data/gho/indicator-metadata-registry/imrdetails/4834\#: :text=Target\%203.8\%20is\%20defined\%20as,medicines\%20and\%20vaccines\%20for\%20all\%E2\%80\%9D. Accessed on 17 July 2020

7. Levinson W, Lesser CS, Epstein RM. Developing physicians communication skills for patient-centered care. Health Affairs. 2010; 29(7):1310-1318.

8. Bertil M, Birgitta A, Ann MS, Birgitta G, Barbro H, Bengt F, Promoting medical self-care: evaluation of a family intervention implemented in the primary health care by pharmacies, Family Practice, Volume 16, Issue 5, October 1999, Pages 522-527, https://doi.org/10.1093/fampra/16.5.522

9. BMJ 2019;365:I1228. http://dx.doi.org/10.1136/bmj.I1228 Accessed on 17 July 2020

10. Panagioti M, Richardson G, Small N, et al. Self-management support interventions to reduce health care utilisation without compromising outcomes: a systematic review and meta-analysis. BMC Health Serv Res 2014; 14:356. doi:10.1186/1472-696314-356

11. WHO consolidated guideline on self-care interventions for health: sexual and reproductive health and rights. Geneva: World Health Organization; 2019. Licence: CC BY-NC-SA 3.0 IGO.

12. https://phkh.nhsrc.pk/sites/default/files/feeds/Karachi\%20Declaration\%20MNCH\%20and\%20FP\%20Best\%20Practices\%20Pakistan\%202009.pdf Accessed on 20 July 2020

13. Path.azureedge.not/media/documents/RH_Outlook_Nov_2017.pdf Accessed on 20 July 2020

14. Burns N, Grove SK. The Practice of Nursing Research; Conduct, Critique and Utilisation. Philadelphia: W.B. Saunders Co, 1993.

15. Rapley P. Self-care: re-thinking the role of compliance. Aus J Adv Nurs 1997; 15:20-25.

\section{Figures}




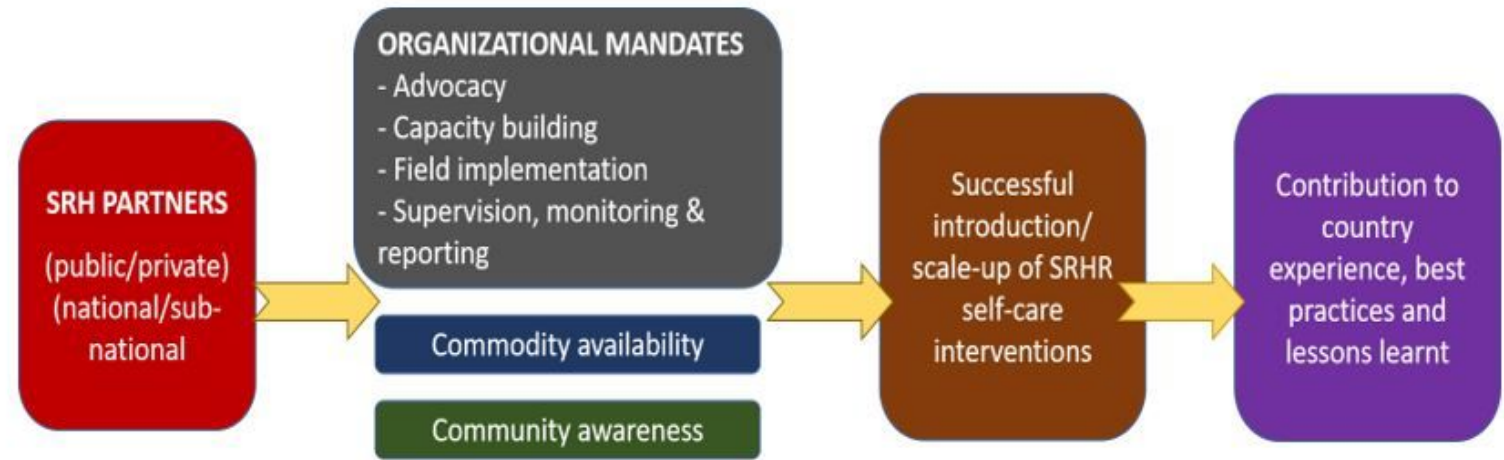

\section{Public sector patronage}

\section{Figure 1}

Conceptual Framework for exploring partner's contribution to SRHR self-care experiences

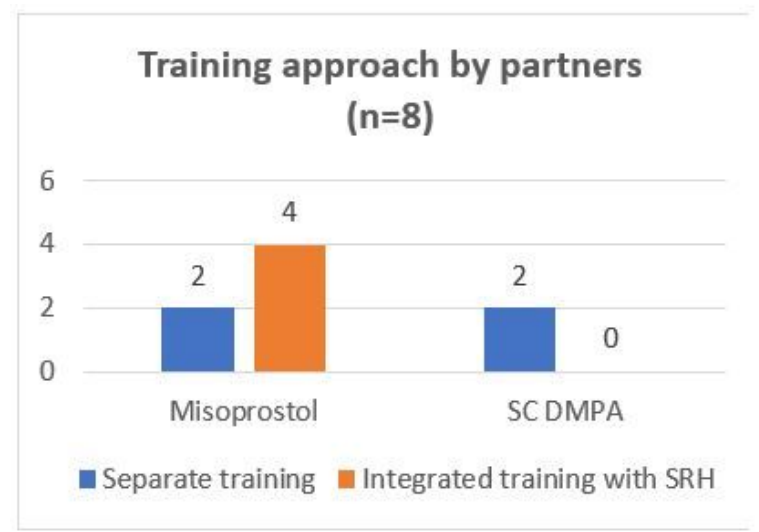

Figure 2

Training approach adopted by SRHR partners who shared their self-care experience

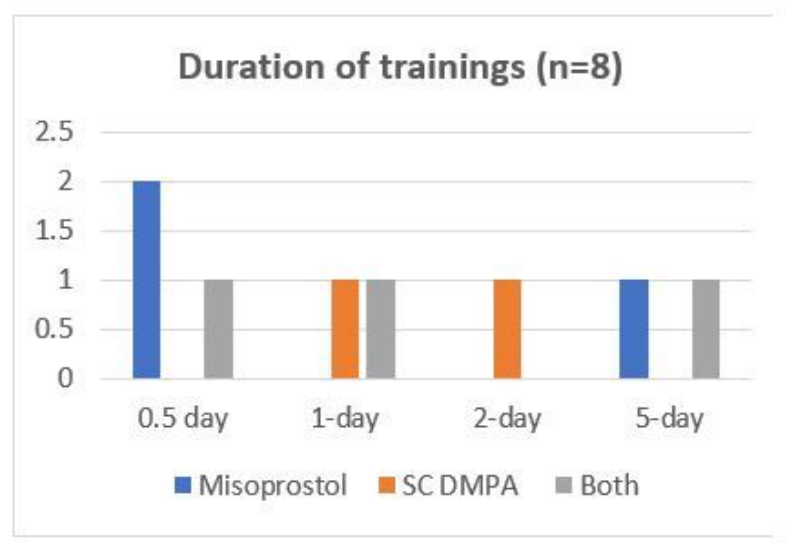

Figure 3

Duration of training sessions on selected two SRHR self-care interventions

\section{Supplementary Files}

This is a list of supplementary files associated with this preprint. Click to download.

- Amaan.docx

- Annex1tool.docx 
- FPAP.docx

- Greenstar.docx

- IMC.docx

- IPAS.docx

- Jhpiego.docx

- NCMNH.docx

- Pathfinder.docx

- Rizconsulting.docx 